\title{
Benefits of Physical Activity for Adolescents with Autism Spectrum Disorders: A Comprehensive Review
}

\author{
Carl Sorensen $\cdot$ Nicole Zarrett
}

Received: 4 June 2014 / Accepted: 7 June 2014 / Published online: 18 June 2014

(C) Springer Science+Business Media New York 2014

\begin{abstract}
Research demonstrates substantial health benefits of physical activity (PA), especially moderate to vigorous physical activity (MVPA). Several studies suggest that MVPA may be especially beneficial to children with autism spectrum disorders (ASD) including improved physiological, cognitive, psychological, and behavioral functioning. However, few PA-based interventions have targeted adolescents with ASD, when PA rates are shown to decline significantly, primarily focusing instead on children with ASD. Furthermore, these studies have varied significantly in methodological rigor, making it difficult to disentangle consistent findings of effective intervention. Given that a majority of adolescents with ASD fail to meet national recommendations for daily PA and demonstrate lower rates of PA relative to their nondisabled peers, identifying effective interventions for this population is needed. The purpose of this systematic review was to collect and synthesize evidence from the studies of PAbased interventions for adolescents with $\operatorname{ASD}(N=19)$ to identify benefits of PA and effective strategies for increasing PA in adolescents with ASD. The strongest empirical support for the benefits of PA was identified for self-regulation, health, and motor skills, while evidence remains limited or absent for benefits related to improvements to cognitive, language, and sensorimotor functioning. Highly effective intervention mechanisms identified included prompting, modeling, praise, and structured teaching.
\end{abstract}

Keywords Adolescents $\cdot$ Physical activity $\cdot$ Exercise . Autism · Disabilities

\footnotetext{
C. Sorensen $(\bowtie) \cdot N$. Zarrett

Department of Psychology, University of South Carolina, 1512

Pendleton Street, Columbia, SC 29208, USA

e-mail: sorensec@email.sc.edu

N. Zarrett

e-mail: zarrettn@mailbox.sc.edu
}

\section{Introduction}

Research demonstrates substantial benefits of physical activity (PA), especially moderate to vigorous physical activity (MVPA), across health domains and across the lifespan including improvements in weight status, cardiovascular health, emotional health, and cognitive performance (Tomporowski et al. 2011). Numerous studies suggest that MVPA may be especially beneficial to children with autism spectrum disorders (ASD; e.g., Lang et al. 2010; Sowa and Muelenbroek 2012), shown to decrease rates of stereotyped and repetitive behaviors (e.g., Bahrami et al. 2012), and improve cognitive performance (Anderson-Hanley et al. 2011), self-regulation (e.g., Allison et al. 1991), classroom performance, attention and compliance (e.g., Reid et al. 1988), and social and emotional functioning (e.g., Pan and Frey 2006; Pan et al. 2011). Although recent reviews (Lang et al. 2010; Sowa and Muelenbroek 2012) provide empirical support for these relations primarily among children with ASD, less is known about whether these relations are applicable to adolescents with ASD, or promising strategies for promoting PA among ASD adolescents. Moreover, previous reviews have not considered the methodological rigor of reviewed studies (e.g., Sowa and Muelenbroek 2012) when evaluating the strength of PA effects on the developmental outcomes of ASD youth.

Adolescence (10-19 years; WHO 2013) has been recognized as a critical period in development during which individuals set behavioral patterns which may last into and through adulthood (Curtin et al. 2010; Pan and Frey 2006) and thus a critical intervention point for PA behavior change. Despite the potential benefits of PA, researchers have documented declines in PA during adolescence (Levinson and Reid 1993; Pate et al. 2006), and increased rates of overweight and obesity (Curtin et al. 2010) for youth with and without ASD, with significantly lower rates of PA among adolescents with ASD relative to their nondisabled peers. Given the importance 
of PA for reducing symptomatology of ASD and promoting healthy development, and the significantly lower rates of PA among adolescents with ASD relative to their nondisabled peers, it is crucial to develop a greater understanding of the benefits of PA and mechanisms for promoting PA for this population.

This review seeks to collect and synthesize evidence for benefits of PA for adolescents with ASD across multiple areas of functioning (health, self-regulation, and cognitive performance), identify effective strategies for promoting PA among adolescents with ASD, and identify gaps in the current literature. To our knowledge, this is the first review of PA-based interventions to focus solely on the effects of PA for ASD adolescents, and to consider the methodological rigor of each study (e.g., measurement, research design, and clear description of procedures) when drawing conclusions across these studies.

\section{Method}

The present study presents a systematic review of research examining the effects of PA on the health and adaptive functioning of adolescents with ASD using a comprehensive search procedure and a priori selection procedures. To identify the studies which met the inclusion criteria of the current review, a literature search was conducted using the following online databases (years 1980 through 2012): PsycINFO, PsycARTICLES, JSTOR, EBSCOhost, Electronic Journals Service, ERIC, ProQuest, PubMed, and Social Sciences Full Text. Studies included in the current review met three criteria: (1) the majority of study participants were adolescents (i.e., age $=10-19$ years); (2) the study measured PA as an independent variable and articulated how PA was measured; and (3) the study examined the effects of PA on adolescents with ASD. Studies that reported only qualitative findings or were theses, dissertations, book chapters, conference proceedings, or unpublished works were excluded.

\section{Calculation}

The current review evaluated methodological rigor using a systematic strategy informed by the American Psychological Association's (APA) Meta-Analysis Reporting Standards (MARS; APA 2008). Studies were evaluated, and then ranked, based on their degree of methodological rigor (see Table 1). These criteria were used to weight the studies for the purpose of assessing the strength of existing evidence for benefits of PA for youth with ASD, and for consideration of the relative merit of studies in the case of conflicting findings. Studies were assigned 1 point for the presence of each methodological rigor criterion (i.e., theory, rationale, design, multiple measures, PA measure, diagnostic criteria, and stated level of cognitive function) and totaled to indicate the study's methodological quality ( 0 to 8 points), with higher scores indicating higher levels of methodological rigor. For example, when assessing the theory-driven criterion, 1 point was assigned if the theory was well justified and incorporated into the study and 0 points were given if researchers did not explain how the theory guided the conceptualization, design, or interpretation of the study/intervention. Studies that received 1 or fewer points were excluded from this review.

\section{Results}

The initial search identified 47 PA-based intervention studies targeting youth with ASD. Of the 47 studies, 28 were excluded from further analysis (13 studies included primarily youth who were not adolescents, 8 studies did not clearly specify which students had ASD, 4 studies did not clearly identify PA as an outcome or predictor, and 3 studies were excluded due to low methodological rigor scores), resulting in a total of 19 studies for analysis.

\section{Study Characteristics}

Methodological rigor scores ranged from 3 to 6 (Table 1). Authors of most studies $(N=17)$ presented reliability estimates for their measures, diagnostic criteria, and a theoretical rationale for their investigation, but only a slight majority $(N=11)$ used a rigorous design to test their hypotheses, and few $(N=5)$ provided a rationale for selecting an adolescent sample (i.e., adolescents vs. youth in general or all ages). All studies ( $N=$ 19) reported overall frequency and duration of PA sessions (e.g., cycling for $20 \mathrm{~min}$, three times per week), but only nine studies clearly articulated the type or intensity of PA and a smaller portion $(N=4)$ reported variable levels of PA within sessions, rendering interpretation of findings across all studies difficult due to uncertainty regarding the relative strength of each manipulation. Few studies individually tailored physical activities to participants (Tables 2 and 3). One study (Cannella-Malone et al. 2011) measured time on-task among teachers (i.e., engaged with intervention activities vs. other tasks), but did not indicate time on-task among students or intensity of student PA within activity intervals (see Table 4).

Few studies used multiple methods of data collection $(N=$ 4 ), or presented the level of cognitive functioning of participants (see Tables 2 and 3). Group interventions used designs with controls $(N=5)$, within person analyses $(N=3)$, or compared changes pre- and postintervention between groups $(N=$ $1)$. The remaining studies were small $N$, or single case designs, employing multiple-baseline $(N=1)$, alternating treatments, reversal or repeated reversal, or $\mathrm{AB}$ designs (see Table 2). 
Table 1 Methodological rigor scores for studies that met inclusion criteria

\begin{tabular}{|c|c|c|c|c|c|c|c|c|c|}
\hline Study & Theory & Rationale & Design & Multimeasure & $\begin{array}{l}\text { Measure } \\
\text { score }\end{array}$ & PA score & $\begin{array}{l}\text { Diagnostic } \\
\text { criteria }\end{array}$ & $\begin{array}{l}\text { Cognitive } \\
\text { function }\end{array}$ & Total \\
\hline Anderson-Hanley et al. (2011) & 1 & 0 & 0 & 0 & 1 & 0 & 1 & 0 & 3 \\
\hline Bahrami et al. (2012) & 0 & 0 & 1 & 0 & 1 & 0 & 1 & 0 & 3 \\
\hline Cannella-Malone et al. (2011) & 1 & 0 & 1 & 0 & 1 & 0 & 1 & 1 & 5 \\
\hline Hillier et al. (2011) & 1 & 1 & 1 & 0 & 1 & 0 & 1 & 0 & 5 \\
\hline Kern et al. (1984) & 1 & 0 & 1 & 1 & 1 & 1 & 1 & 0 & 6 \\
\hline Kern et al. (1982) & 0 & 0 & 1 & 0 & 1 & 0 & 1 & 1 & 4 \\
\hline Levinson and Reid (1993) & 1 & 0 & 0 & 1 & 1 & 1 & 1 & 0 & 5 \\
\hline Lochbaum and Crews (2003) & 0 & 0 & 0 & 1 & 1 & 1 & 1 & 1 & 5 \\
\hline Morrison et al. (2011) & 1 & 0 & 1 & 0 & 1 & 0 & 0 & 0 & 3 \\
\hline Movahedi et al. (2013) & 0 & 1 & 1 & 0 & 1 & 0 & 1 & 0 & 4 \\
\hline Pan (2009) & 1 & 1 & 0 & 0 & 1 & 1 & 1 & 0 & 5 \\
\hline Pan (2011) & 1 & 0 & 1 & 0 & 1 & 1 & 1 & 0 & 5 \\
\hline Pan et al. (2011) & 1 & 0 & 0 & 0 & 1 & 1 & 1 & 0 & 4 \\
\hline Pitetti et al. (2007) & 0 & 0 & 1 & 1 & 1 & 1 & 1 & 1 & 6 \\
\hline Reid et al. (1988) & 1 & 0 & 1 & 0 & 1 & 0 & 0 & 1 & 4 \\
\hline Rosenthal-Malek and Mitchell (1997) & 0 & 1 & 0 & 0 & 1 & 0 & 0 & 1 & 3 \\
\hline Todd and Reid (2006) & 1 & 1 & 0 & 0 & 0 & 1 & 1 & 1 & 5 \\
\hline Todd et al. (2010) & 1 & 0 & 1 & 0 & 0 & 1 & 1 & 1 & 5 \\
\hline Watters and Watters (1980) & 1 & 0 & 0 & 0 & 1 & 0 & 1 & 1 & 4 \\
\hline Total & 14 & 5 & 11 & 4 & 17 & 9 & 16 & 9 & $M=4.42$ \\
\hline
\end{tabular}

Criteria adapted from APA MARS standards (APA 2008)

$1=$ met criterion, $0=$ did not meet criterion

\section{Participant Characteristics}

Table 3 summarizes the sample characteristics of included studies (i.e., sample size, demographic information, level of cognitive functioning, and diagnostic criteria and intervention setting). Across all studies, PA was observed in 215 adolescents with ASD and 76 youth without an ASD diagnosis. A majority of these studies included only, or mostly, males, which is expected given the largely disproportionate male to female ratio observed in the ASD population (APA 2013). The mean age for participants was 12.54 (range $=4-27$ years). ASD was the most commonly reported diagnosis $(N=176)$, followed by DSM-IV diagnoses that are now subsumed under ASD, according to the current DSM-V formulation (APA 2013). Few studies noted demographic information other than sex. Hillier et al. (2011) noted the race/ethnicity of participants and Pan (2009) stated that participants were from an urban area typified by low socioeconomic status. Other authors (Bahrami et al. 2012; Movahedi et al. 2013; Pan 2009, 2011; Pan et al. 2011) indicated locations for their studies that suggest additional diversity factors (i.e., Iran and Taiwan).

Among these studies reporting participants' baseline levels of cognitive or adaptive functioning, those that reported level of cognitive functioning included only participants with intellectual disabilities (i.e., IQ < 70). Of those studies that did not report level of cognitive functioning, four (Table 3) reported data from reliable and valid clinical measures of adaptive functioning (i.e., Gilliam Autism Rating Scale-Second Edition; GARS-2, Vineland Adaptive Behaviors Scales; VABS). Other studies (Hillier et al. 2011; Levinson and Reid 1993; Pan 2009, 2011; Pan et al. 2011) reported qualitative descriptions of level of functioning, but did not give a detailed account, clearly specify domain of functioning (e.g., cognitive, adaptive behavior, and symptom severity), or specify a standardized instrument used to make determinations regarding level of functioning.

\section{Benefits of PA for ASD}

Targeted outcomes for all studies that met the inclusion criteria are displayed in Table 4. The table summarizes main findings for benefits of PA on the health and functioning of adolescents with ASD.

\section{Medical Health and Physical Fitness}

Of the six studies examining the effects of PA on the physical health of adolescents with ASD, five found beneficial effects including motor skills (Pan 2011; Pitetti et al. 2007), endurance (Pan 2011; Todd and Reid 2006; Todd et al. 2010), 
Table 2 Study characteristics

\begin{tabular}{|c|c|c|c|c|}
\hline Study & Theory & Rationale & Design & PA measurement \\
\hline Anderson-Hanley et al. (2011) & EF deficit & NS & Pre-post & Set interval \\
\hline Bahrami et al. (2012) & NS & NS & Randomized group/control & Set interval \\
\hline Cannella-Malone et al. (2011) & Behavioral & NS & Multiple baseline & Set intervals \\
\hline Hillier et al. (2011) & Physiological & $\begin{array}{l}\text { Expansion of services } \\
\text { and need for objective } \\
\text { measures }\end{array}$ & Group repeated measures & Set interval \\
\hline Kern et al. (1984) & Behavioral & NS & Alternating treatments & $\begin{array}{l}\text { Behavioral indicator of VPA, } \\
\text { set interval }\end{array}$ \\
\hline Kern et al. (1982) & Behavioral & NS & Repeated reversal & Set interval \\
\hline Levinson and Reid (1993) & Behavioral & NS & $\mathrm{ABCA}$ & HR, Distance/15 min \\
\hline Lochbaum and Crews (2003) & NS & NS & Pre-post & $\mathrm{HR}$, max weight, set interval \\
\hline Morrison et al. (2011) & Behavioral & NS & $\mathrm{ABA}$ & Set intervals \\
\hline Movahedi et al. (2013) & NS & $\begin{array}{l}\text { Intervene early to arrest } \\
\text { delayed learning }\end{array}$ & Randomized group/control & Set intervals \\
\hline $\operatorname{Pan}(2009)^{\mathrm{a}}$ & SDT & $\begin{array}{l}\text { Lower PA levels in } \\
\text { adolescence }\end{array}$ & Correlational & Accelerometer \\
\hline Pan (2011) & SDT & NS & $\begin{array}{l}\text { Randomized mixed within } \\
\text { and between }\end{array}$ & Set interval \\
\hline Pan et al. $(2011)^{\mathrm{a}}$ & SDT & NS & Correlational & Accelerometer \\
\hline Pitetti et al. (2007) & NS & NS & Randomized, control group & $\begin{array}{l}\text { Min/session, day/week, speed, } \\
\text { treadmill incline, energy } \\
\text { expenditure }\end{array}$ \\
\hline Reid et al. (1988) & SDT & NS & $\mathrm{ABA}$ & Set interval \\
\hline Rosenthal-Malek and Mitchell (1997) & NS & $\begin{array}{l}\text { Benefits }+ \text { insufficient } \\
\text { research focused on } \\
\text { adolescents }\end{array}$ & Pre-post & Set interval \\
\hline Todd and Reid (2006) & SDT & $\begin{array}{l}\text { Benefits }+ \text { insufficient } \\
\text { research focused on } \\
\text { adolescents }\end{array}$ & $\mathrm{ABCA}$ & Distance \\
\hline Todd et al. (2010) & SDT & NS & Multiple baseline & Distance, speed \\
\hline Watters and Watters (1980) & Behavioral & NS & Pre-post & Set interval \\
\hline
\end{tabular}

$N S$ not specified, SDT self-determination theory, $H R$ heart rate

${ }^{\text {a }}$ Correlational

strength (Lochbaum and Crews 2003; Pan 2011), cardiovascular (Pan 2011) and aerobic (Lochbaum and Crews 2003) fitness, and flexibility (Pan 2011), while Kern et al. (1982) failed to find improvements in motor skills following PA. Only two studies that met inclusion criteria examined relationships between body composition and PA among adolescents with ASD, despite the high number of publications examining these relationships among typically developing youth (Pan 2011; Pitetti et al. 2007). While Pitetti et al. (2007) found a moderate decrease in BMI following treadmill jogging, Pan (2011) failed to find a significant effect on BMI following aquatic exercise.

\section{Self-regulation}

A large number of studies $(N=15)$ examined relationships with self-regulation which may be due to the critical importance of reducing harmful behaviors (e.g., aggression and self-injury) and high social validity of such treatment goals. All studies $(N=9)$ examining stereotyped and repetitive behaviors reported decreases associated with increases in PA, but the duration of intervention effects varied. Two studies reported results at long-term follow-up (Bahrami et al. 2012; Movahedi et al. 2013), with only one (Bahrami et al. 2012) finding sustained benefits. Levinson and Reid (1993) reported decreases in stimulatory behaviors during and immediately after exercise, but a return to baseline levels after $90 \mathrm{~min}$. Of the five studies comparing light PA and MVPA, five found greater improvements for MVPA (e.g., jogging) than for light PA or sedentary behavior (e.g., walking); Kern et al. (1982, 1984) reported some benefit of light PA, but others (Levinson and Reid 1993; Pan 2009; Pan et al. 2011) found beneficial effects for MVPA only. Other studies using duration/ frequency of PA session as a PA indicator $(N=6)$ reported decreased rates of aberrant behaviors and inappropriate 
Table 3 Sample characteristics of reviewed studies

\begin{tabular}{|c|c|c|c|c|c|c|}
\hline Study & Sample size & $\begin{array}{l}\text { Age in years } \\
\text { M (range) }\end{array}$ & $\begin{array}{l}\text { Diversity } \\
\text { factors }\end{array}$ & Functioning & Criteria for diagnosis & Setting \\
\hline Anderson-Hanley et al. (2011) & $N=22(\mathrm{Fm}=4)$ & $14(8-21)$ & NS & $\mathrm{NS}^{\mathrm{a}}$ & DSM-IV-TR & School \\
\hline Bahrami et al. (2012) & $N=30(\mathrm{Fm}=4)$ & $9(5-16)$ & Iran & $\mathrm{NS}^{\mathrm{a}}$ & DSM-IV-TR & Sports facility \\
\hline Cannella-Malone et al. (2011) & 3 & $9(8-11)$ & NS & Low & Prev Dx & School \\
\hline Hillier et al. (2011) & $N=18(\mathrm{Fm}=2)$ & $17(13-27)$ & Race & NS & Previous Dx & University \\
\hline Kern et al. (1984) & $N=3$ & $10(7-11)$ & NS & $\mathrm{NS}^{\mathrm{a}}$ & $\begin{array}{l}\text { Two independent diagnosticians; } \\
\text { criteria: (NSAC, 1978) }\end{array}$ & Home, open field \\
\hline Kern et al. (1982) & $N=7(\mathrm{Fm}=2)$ & $9(4-14)$ & NS & Low & $\begin{array}{l}\text { Two independent diagnosticians; } \\
\text { criteria: (NSAC, 1978) }\end{array}$ & Open field, clinic \\
\hline Levinson and Reid (1993) & $N=3(\mathrm{Fm}=1)$ & 11 & NS & NS & Dx by neurologist, DSM-III & School \\
\hline Lochbaum and Crews (2003) & $N=5$ & $18(16-21)$ & NS & Low & School psychologist; DSM-IV & Not specified \\
\hline Morrison et al. (2011) & $N=4(\mathrm{Fm}=2)$ & $14(10-21)$ & NS & NS & NS & NS \\
\hline Movahedi et al. (2013) & $N=26(\mathrm{Fm}=4)$ & $9(5-16)$ & Iran & NS & DSM-IV-TR & Sports facility \\
\hline Pan (2009) & $N=25$ & $9(7-12)$ & Taiwan, SES & NS & Medical diagnosis, DSM-IV & School \\
\hline Pan (2011) & $N=15$ & $9(7-12)$ & Taiwan & NS & Medical diagnosis, DSM-IV & School \\
\hline Pan et al. (2011) & $N=100(\mathrm{ASD}=25)$ & $14(13-15)$ & Taiwan & NS & Physician diagnosis & School \\
\hline Pitetti et al. (2007) & $N=10(\mathrm{Fm}=4)$ & $17(14-19)$ & NS & Low & $\begin{array}{l}\text { Physical and psychologist, } \\
\text { DSM-IV-TR }\end{array}$ & Residential school \\
\hline Reid et al. (1988) & $N=3$ & $16(12-17)$ & NS & Low & NS & School \\
\hline $\begin{array}{l}\text { Rosenthal-Malek and } \\
\text { Mitchell (1997) }\end{array}$ & $N=5$ & $15(14-15)$ & NS & Low & NS & School \\
\hline Todd and Reid (2006) & $N=3$ & $17(15-20)$ & NS & Low & Interdisciplinary team, DSM-IV & School \\
\hline Todd et al. (2010) & $N=3(\mathrm{Fm}=1)$ & $16(15-17)$ & NS & Low & Interdisciplinary team, DSM-IV & School \\
\hline Watters and Watters (1980) & $N=5$ & $10(9-11)$ & NS & Low & Previous diagnosis & School \\
\hline
\end{tabular}

NS not specified

${ }^{\text {a }}$ Indicates clinical measure presented rather than cognitive measure

vocalizations $(N=2)$, improved self-management $(N=2)$, improved social and emotional functioning $(N=3)$, and increases in productivity with regards to vocational tasks $(N=1)$. Only one study examined the effects of PA on prosocial behavior or appropriate communication (Reid et al. 1988), but did not find significant effects of PA.

\section{Cognitive Function and Academic Performance}

Despite numerous studies reporting the relationships between increases in PA and cognitive performance among typically developing individuals (Tomporowski et al. 2011), as well as evidence that bouts of PA can increase cognitive performance among adolescents with non-ASD developmental disabilities and clinical diagnoses (Tomporowski 2003), only one study examined cognitive outcomes. Anderson-Hanley et al. (2011) reported increases in cognitive function associated with increased PA for adolescents with ASD. Three studies, however, examined classroom performance, attention, and compliance with increases in PA (Kern et al. 1982; Reid et al. 1988; Rosenthal-Malek and Mitchell 1997), each reporting beneficial effects of PA.
Effective Intervention Mechanisms

Among the intervention studies, most described their teaching procedures $(N=17)$. Given that the majority of interventions used are behavioral (B) or self-determination theory (SDT) theoretical paradigm, the most common intervention strategies were encouragement (SDT), praise (B), and prompts (B), followed by stimulus control (B), modeling (B), tangible reinforcement (B), goal-setting (SDT), and self-monitoring (B; Table 2). While encouragement, prompting, and modeling appear to have been the most common and most effective techniques, the largest sustained effect size, and only reported effect maintained at long-term follow-up (Bahrami et al. 2012), was associated with highly structured teaching practices based on the University of North Carolina's TEACCH methods (e.g., visual supports, structured activities/environments; Schultheis et al. 2000). Similarly, Cannella-Malone et al. (2011) reported reductions in aggression (87-99 \% decrease) during a highly structured and monitored exercise intervention, and Pan (2009) reported a large effect size $(r=0.74)$ between MVPA and social engagement for PE class but not recess. It may be the case that highly 
Table 4 Study outcomes assessed, type of PA implemented, and key findings for all reviewed studies

\begin{tabular}{|c|c|c|}
\hline Study & Outcome & $\begin{array}{l}\text { Description of PA (type, intensity, } \\
\text { frequency, duration) }\end{array}$ \\
\hline $\begin{array}{l}\text { Anderson-Hanley } \\
\text { et al. (2011) }\end{array}$ & $\begin{array}{l}\text { RRB: GARS-2; EF: DSF, } \\
\text { DSB, color trails test, stroop }\end{array}$ & Cybercycling (20 min) \\
\hline Bahrami et al. (2012) & RRB: GARS-2 & $\begin{array}{l}\text { Kata: warm-up }(15 \mathrm{~min}) \\
\text { lesson }(65 \mathrm{~min}), \text { cool down } \\
\text { (10 } \mathrm{min})\end{array}$ \\
\hline $\begin{array}{l}\text { Cannella-Malone } \\
\text { et al. (2011) }\end{array}$ & AGG: FREQ & $\begin{array}{l}\text { Aerobic, resistance, stretch, } \\
\text { scooterboard, calisthenics; } \\
20 \mathrm{~min}, 2 / \text { day }+1-5 \mathrm{~min} / \mathrm{h}\end{array}$ \\
\hline Hillier et al. (2011) & STR: CORT, ANX: STAI & $\begin{array}{l}75 \mathrm{~min}, 1 / \text { week; } 5-10 \mathrm{~min} / \text { activity, } \\
\text { low intensity; }<10 \mathrm{~min} \\
\text { continuous MPA }\end{array}$ \\
\hline Kern et al. (1984) & RRB: TS & Jogging (15 min), catch (15 min) \\
\hline Kern et al. (1982) & $\begin{array}{l}\text { RRB, MOT, ON/OFF: } \\
\text { TS; ACE: Count }\end{array}$ & Jogging (20 min) \\
\hline $\begin{array}{l}\text { Levinson and } \\
\quad \text { Reid (1993) }\end{array}$ & RRB, SIB: TS & Jog (15 min), walk (15 min) \\
\hline $\begin{array}{l}\text { Lochbaum and } \\
\text { Crews (2003) }\end{array}$ & FIT: PWC & $\begin{array}{l}\text { Stationary bike }(20 \mathrm{~min} \text {, } \\
\text { 3/week }) \text {, resistance } \\
(1 \mathrm{~h}, 2-3 / \text { week })\end{array}$ \\
\hline Morrison et al. (2011) & RRB, SIB:TS & $\begin{array}{l}\text { 10-min therapy ball, scooter } \\
\text { boards, stationary bike, } \\
\text { moon shoes }\end{array}$ \\
\hline Movahedi et al. (2013) & SOC: GARS-2 & $\begin{array}{l}\text { Kata: warm-up (15 min), } \\
\text { Lesson }(65 \mathrm{~min}), \text { cool } \\
\text { down }(10 \mathrm{~min})\end{array}$ \\
\hline Pan (2009) & SOC: Engagement check & Varied PA \\
\hline
\end{tabular}

Pan (2011)

FIT: PACER, BIA, PT; MOT: HAAR

Aquatic exercise, $60 \mathrm{~min}$

Pan et al. (2011)

Pitetti et al. (2007)

Reid et al. (1988)

Rosenthal-Malek and Mitchell (1997)
SR, SOC: MPES

FIT: PA-CAP, WT, BMI; CAL: $\mathrm{kcal} / \mathrm{min}$

ON/OFF, RRB, VOC, COM, PSB: TS

ACE, WORK, RRB: TS
Findings

RRB: decrease $\left(\eta p^{2}=.24-.47\right)$; EF: increase (DSB; $\eta p^{2}=.20-.22$ )

RRB: decrease for Kata group (42.54\%). gains maintained at 30-day follow-up

AGG: decrease (87-99 \%)

STR, ANX: decreased CORT $(\eta 2=0.482)$ and STAI $(\eta 2=0.456)$ after PA, but not across weeks

RRB: greater reduction for jog (58\% of intervals), than catch $(78 \%)$

ON/OFF, ACE, RRB: greater improvement in jogging condition

RRB: post-jog decrease (17.5\%), but not for walk. Temporary: return to baseline levels after $90 \mathrm{~min}$

FIT (aerobic): all improved 33-50 \%; (strength): only participant 1 (19-47\%) and $2(12-28 \%)$

RRB, SIB: decreased in Tx phase for all; (males): pre- to post-decrease for exercise only; (Females): No pre-post decrease

SOC: decrease for $\operatorname{Tx}\left(\eta^{2}=.38\right)$, but not CON. Not significant at follow-up

SOC: VPA $(r=0.74)$ and steps $/ \mathrm{min}$ $(r=0.51)$ correlated with noninteractive engagement with adults during PE, but not recess

Tx/ASD $>$ CON/ASD: 30 s curl-ups $(\mathrm{d}=1.18)$, aquatic skills (stages IV $[d=1.24]$ and $\mathrm{V}[d=1.32])$

Tx/ASD > TD/CON: 30 s curl-ups $(d=1.54), 60$ s curl-ups $(d=1.39)$, aquatic skills (stages II [ $d=1.48]$ and IV $[d=1.83]$, and V $[d=1.56])$

CON/ASD <TX/TD: 60 s curl-ups $(d=1.22)$ and aquatic skills at stages IV $(d=1.53)$

BMI, \%body fat $=$ NS

PA: ASD $<$ TD. Introjected SOC associated with MVPA $(r=.50)$ and moderate PA $(r=.58)$

FIT: WT $=$ NS, BMI $(d=.38)$; CAL: change from 1 st to last month $=443.2 \%$; PA-CAP: inconsistent

ON: increase (28\%), OFF: decreased (43\%), RRB: decrease (23\%), VOC: decrease $(20 \%)$

ACE: PA>CON: ACE $(M=33.6$ vs. 29.6) and WORK ( $M=24.3$ vs. 21.8), RRB: $\mathrm{PA}<\mathrm{CON}$ 
Table 4 (continued)

\begin{tabular}{llll}
\hline Study & Outcome & $\begin{array}{l}\text { Description of PA (type, intensity, } \\
\text { frequency, duration) }\end{array}$ & Findings \\
\hline Todd and Reid (2006) & $\begin{array}{c}\text { FIT: Count; SR: increase in } \\
\text { laps + decrease in EXT } \\
\text { Todd et al. (2010) } \\
\text { SR: accuracy in meeting goals; } \\
\text { SE: proportion of "I can } \\
\text { responses," FIT: count and speed }\end{array}$ & Jogging, snowshoing, 30 min & FIT: increased 300\%, despite faded EXT \\
$\begin{array}{l}\text { Watters and } \\
\text { Watters (1980) }\end{array}$ & ACE, RRB: TS & Jogging, 8-10 min & $\begin{array}{c}\text { Increase in distance traveled over 30 min, } \\
\text { increase in "I can" response }\end{array}$ \\
\hline
\end{tabular}

$R R B$ repetitive and restrictive patterns of behavior and interests, GARS-2 Gilliam Autism Rating Scale-Second Edition, $E F$ executive function, $D S F$ digit span forward, DSB digit span backward, AGG aggression, FREQ frequency, FIT fitness, MOT motor skills, PT performance test, STR stress, CORT cortisol, $A N X$ anxiety, $S T A I$ state-trait anxiety inventory, $T S$ time sampling, $O N / O F F$ on or off task, $A C E$ academic task, Count count or total number, $S I B$ self-injurious behavior, $P W C$ Power Work Capacity fitness test, $S O C$ social engagement, $P A C E R$ Progressive Aerobic Cardiovascular Endurance Run, $B I A$ bioelectric impedance analysis, HAAR Humphries' Assessment of Aquatic Readiness, SR self-regulation, EXT external motivation (e.g., reinforcement, prompting), MPES Motivation in Physical Education Scale, PA-CAP PA/exercise capacity, $W T$ weight, $B M I$ body mass index, $C A L$ caloric expenditure (e.g., kcal/min), VOC inappropriate vocalizations, COM communication, $P S B$ pro-social behavior, WORK work productivity, $S E$ selfefficacy

structured environments are beneficial to adolescents with ASD, particularly when engaging in group activities.

\section{Discussion and Conclusions}

The present review serves to clarify disparate evidence regarding the benefits of PA for adolescents with ASD and to identify effective strategies for increasing their active engagement in PA. Studies $(N=19)$ describing relationships between PA and adolescent functioning suggest promising avenues for expanding and improving educational and health promotion of youth programming for this population across several domains (e.g., physical and mental health, self-regulation, cognitive development, and social-emotional functioning).

\section{Conclusions}

The existing literature suggests an emerging evidence-base for benefits of PA for adolescents with ASD. The strongest evidence from the present review supports benefits related to motor development and physical fitness and decreases in repetitive, stereotyped, and self-injurious behaviors, yielding the largest number of moderate to strong effect sizes. Despite lower levels of representation in the literature, socialemotional effects of PA also yielded relatively large effects (e.g., Pan 2009). The present review revealed minimal evidence of increases in cognitive performance for adolescents, but some evidence for improvements in executive function specifically (e.g., working memory, cognitive control/ attention, and goal-setting), as well as some evidence for benefits related to self-regulation (e.g., decreases in aggression and disruptive behaviors). However, more research is needed regarding the effects of PA on specific facets of cognitive ability and executive function to further clarify this nuanced relationship.

Highly promising intervention strategies include prompts, modeling, praise, and structured teaching. The only study reporting effects at follow-up (Bahrami et al. 2012) used highly structured teaching techniques similar to the TEACCH model. Emerging evidence also exists for SDTrelated approaches (e.g., goal-setting, promotion of autonomy, and self-efficacy; Pan 2011; Todd and Reid 2006; Todd et al. 2010). Additionally, stronger effects were associated with MVPA versus light PA such that effects were reported for MVPA only (Kern et al. 1982; Levinson and Reid 1993; Pan et al. 2011), or stronger effects for MVPA (jogging) than for light PA (catch; Kern et al. 1984).

\section{Limitations}

To date, there is a relative paucity of research examining the benefits of PA for adolescents with ASD. No large RCTs were identified for the present review, and few smaller-scale studies used highly rigorous designs such as multiple baseline or repeated reversals, thus limiting the strength of inferences that can be drawn from this literature. Larger-scale studies, or smaller-scale studies which employ highly rigorous designs, may help to increase generalizability and increase the power of studies to examine contextual factors related to promoting MVPA among this population. This lack of research is particularly surprising due to (1) the higher risk of chronic disease, (2) higher rates of overweight and obesity, (3) higher rates of sedentary behavior, (4) lower rates of PA among adolescents with ASD relative to nonaffected peers, and (5) studies demonstrating similar benefits (e.g., health, cognitive, emotional, and behavioral) for typically developing individuals during adolescence, and across the lifespan. Despite the exciting 
potential for this line of research, there may be several reasons for a lack of studies focusing on this topic, including (1) greater interest in reducing aberrant behaviors and increasing key skills such as communication, (2) greater interest in early intervention (age $<5$ years) or failure to identify adolescence as a particularly important period for PA-related intervention, and (3) substantial barriers to implementation of PA interventions for this population.

ASD is frequently accompanied by severe and potentially dangerous behavioral disruptions, intellectual disabilities, and difficulties with communication, which may substantially interfere with academic, social, and family functioning. Immediate concerns such as these may attract more attention from researchers than interventions that may be commonly perceived as secondary (or even tertiary) such as those designed to develop or build upon strengths, improve adaptive functioning, and increase opportunities for recreation.

Finally, core symptoms of ASD (i.e., social-communication deficits, RRB), co-occurring symptoms (e.g., attention, selfregulation, sensorimotor, and language), and specialized training needed to facilitate effective work with individuals on the autism spectrum may present barriers to implementing PA. Furthermore, it is often the case that youth with ASD may have additional health problems (e.g., physical disabilities and seizure disorders) or take prescription medications that may impair or limit the duration for which they can safely participate (Schultheis et al. 2000). Due to the heterogeneous nature of individuals with ASD, there typically is a substantial variation in symptom presentation within the same setting (e.g., special education classroom and day program), increasing the difficulty of designing and tailoring activities that are appropriate for all ASD youth within group settings and/or generalizable across settings/studies. Consequently, many professionals and paraprofessionals may demonstrate low motivation to engage youth with ASD in PA activities due to concerns about logistical issues involved in tailoring and implementing PA activities with ASD youth (e.g., adapting activities for heterogeneous groups, behavior management, assuring safety, and communication difficulties), such that even program staff with substantial experience working with adolescents with ASD may be hesitant to implement PA activities with groups of ASD youth.

\section{Future Research}

More research is needed to overcome barriers to implementation of both PA interventions and research into the benefits of PA for adolescents with ASD. More research is needed to examine dose-response effects for differing levels of PA. The majority of studies failed to include any measurement of PA intensity or measure variations in outcomes by degree of PA intensity (e.g., MVPA vs. light PA). The few studies that compared the benefits of more intense PA (e.g., jogging) versus less intense forms (e.g., walking and playing catch) found that more vigorous PA was more beneficial, and that effects of PA on adolescent functioning may only be present when youth engage in MVPA (e.g., Kern et al. 1982, 1984; Levinson and Reid 1993; Pan 2009; Pan et al. 2011). Additionally, several factors that may impede engagement with MVPA for youth with ASD should also be assessed including delays in sensorymotor development, anxieties about or low motivation to engage in strenuous or group activities (e.g., team sports), difficulties in planning and self-regulation, and atypical pain sensitivity (Pan and Frey 2006; Reid et al. 1988; Schultheis et al. 2000). No studies in the present review, however, carefully investigated these factors as variables of interest.

Studies which identify optimal settings for implementation of PA activities for adolescents with ASD may be especially useful to researchers and practitioners. Few studies identified by this review systematically compare effect sizes for individual and group PA interventions for youth with ASD. A recent metaanalysis (Sowa and Muelenbroek 2012) found greater effects for individually focused youth PA interventions, particularly in motor and social domains. Similarly, Tomporowski (2003) reported larger effect sizes for individual interventions than for group interventions across studies examining effects of PA on both unaffected youth and those who present with inattention, impulsivity, and hyperactivity. Schleien et al. (1988) found that the types of activities and settings children experienced (i.e., parallel, or cooperative/competitive dyads vs. larger group, team play) during inclusive PE had differential effects on play behaviors and social reciprocity of younger children with ASD, but did not find these relationships for adolescents with ASD. Several studies identified by the present review, however, demonstrated substantial effect sizes for highly-structured PA interventions in group settings. It may be that group activities in appropriately structured environments may serve as a behavioral prosthetic that facilitates social skill development for youth with ASD. Additional studies comparing group and individual PA for youth with ASD may benefit from investigation of unique opportunities for socialization within PE and other structured PA contexts.

Traditional structured contexts for PA may, however, include barriers for some adolescents with ASD (e.g., distractions and loud noises). Tailoring activities and environments to the characteristics of participants may help to overcome some of these barriers (Schultheis et al. 2000), but few studies clearly specified individually tailored interventions beyond monitoring the students for safety or use of adapted equipment. No studies clearly indicated a preference assessment that was specifically intended to increase engagement or intrinsic motivation. Morrison et al. (2011) reported using a preference assessment as part of a functional behavior analysis, but not as an explicit attempt to individually tailor activities. Cannella-Malone et al. (2011) incorporated activity choice into their intervention, but as an addition rather than part of their original design. Todd et al. (2010) used visual 
supports to assess self-efficacy and to support nonverbal participants with goal-setting, self-monitoring, and selfreinforcement, but did not report individually tailored activities. Effective environmental and procedural supports (e.g., developmentally tailored activities and visual supports), represent a substantial opportunity to improve service provision for adolescents with ASD.

In order to make more valid comparisons with research targeting typically developing youth and to help researchers identify additional social and ecological barriers to PA for youth with ASD, more research is needed with regard to multicultural considerations that may influence relationships between PA and adolescent health. Studies collected for the present review contained little data on diversity factors (e.g., race, SES, and sex) that research with typically developing youth has identified as related to knowledge and value of PA as well as social support for PA. Only one study (Hillier et al. 2011) included participant race. Pan (2009) stated that their sample was drawn from a low-SES urban area, but did not provide indicators such as household income or maternal education level. Future studies should increase the amount of information regarding sample characteristics included in publications.

Lastly, only one study described behavioral gains that were maintained at long-term follow-up (Bahrami et al. 2012), and only one other study was identified which conducted long-term follow-up (Movahedi et al. 2013). Several studies reported only immediate effects of PA on adolescent functioning (e.g., results were present within, but not between, sessions; return to baseline within $90 \mathrm{~min}$ of withdrawal of the intervention). Interventions that target the PA-related skills and motivation of program staff may increase the sustainability of interventions and duration of benefits for youth with ASD. Additionally, future studies that target youth directly should focus on intrinsic motivation for PA such that the behavior will persist once external incentives and prompts are withdrawn. Research indicates that interventions for youth with and without ASD that incorporate appropriate adaptations, modeling, encouragement, and that are highly engaging (Lang et al. 2010; Pan et al. 2011; Rimmer 2006; Zarrett and Eccles 2009) most effectively and sustainably increase PA behaviors. It is thus of critical importance to communicate the utility of individually tailored and developmentally appropriate youth programing to parents, educators, clinicians, and the general public in order to develop and maintain increasingly engaging youth programming for adolescents at all levels of functioning.

\section{References}

Allison, D. B., Basile, V. C., \& MacDonald, R. B. (1991). Brief report: comparative effects of antecedent exercise and Lorazepam on the aggressive behavior of an autistic man. Journal of Autism and Developmental Disorders, 21, 89-94.
American Psychiatric Association (APA). (2013). Diagnostic and statistical manual of mental disorders (5th ed.). Washington, DC: American Psychiatric Association.

Anderson-Hanley, C., Turek, K., \& Schneiderman, R. L. (2011). Autism and exergaming: effects on repetitive behaviors and cognitions. Psychology Research and Behavior Management, $1,129-137$.

APA Publications and Communications Board Working Group on Journal Article Reporting Standards. (2008). Reporting standards for research in psychology: why do we need them? What might they be? American Psychologist, 63, 842-845.

Bahrami, F., Movahedi, A., Marandi, S. M., \& Abedi, A. (2012). Kata techniques training consistently decreases stereotypy in children with autism spectrum disorder. Research in Developmental Disabilities, 4, 1183-1193. doi:10.1016/j.ridd.2012.01.018.

Cannella-Malone, H. I., Tullis, C. A., \& Kazee, A. R. (2011). Using antecedent exercise to decrease challenging behavior in boys with developmental disabilities and an emotional disorder. Journal of Positive Behavior Interventions, 13, 230-239.

Curtin, C., Anderson, S. E., Must, A., \& Bandini, L. (2010). The prevalence of obesity in children with autism: a secondary data analysis using nationally representative data from the National Survey of Children's Health. BMC Pediatrics, 10, 11. doi:10.1186/1471-2431$10-11$.

Hillier, A., Murphy, E., \& Ferrara, C. (2011). A pilot study: short-term reduction in salivary cortisol following low level exercise and relaxation among adolescents and young adults on the autism spectrum. Stress and Health: Journal of the International Society for the Investigation of Stress, 27, 395402.

Kern, L., Koegel, R. L., Dyer, K., Blew, P. A., \& Fenton, L. R. (1982). The effects of physical exercise on self-stimulation and appropriate responding in autistic children. Journal of Autism and Developmental Disorders, 12, 399-419.

Kern, L., Koegel, R. L., \& Dunlap, G. (1984). The influence of vigorous versus mild exercise on autistic stereotyped behaviors. Journal of Autism and Developmental Disorders, 14, 57-67.

Lang, R., Koegel, L. K., Ashbaugh, K., Regester, A., Ence, W., \& Smith, W. (2010). Physical exercise and individuals with autism spectrum disorders: a systematic review. Research in Autism Spectrum Disorders, 4, 565-576.

Levinson, L. J., \& Reid, G. (1993). The effects of exercise intensity on the stereotypic behaviors of individuals with autism. Adapted Physical Activity Quarterly, 10, 255-268.

Lochbaum, M., \& Crews, D. (2003). Viability of cardiorespiratory and muscular strength programs for the adolescent with autism. Complementary Health Practice Review, 8, 225-233.

Morrison, H., Roscoe, E. M., \& Atwell, A. (2011). An evaluation of antecedent exercise on behavior maintained by automatic reinforcement using a three-component multiple schedule. Journal of Applied Behavior Analysis, 44, 523-541.

Movahedi, A., Bahrami, F., Marandi, M., \& Abedi, A. (2013). Improvement in social dysfunction of children with autism spectrum disorder following long term Kata techniques training. Research in Autism Spectrum Disorders, 7, 1054-1061.

Pan, C. Y. (2009). Age, social engagement, and physical activity in children with autism spectrum disorders. Research in Autism Spectrum Disorders, 3, 22-31.

Pan, C. Y. (2011). The efficacy of an aquatic program on physical fitness and aquatic skills in children with and without autism spectrum disorders. Research in Autism Spectrum Disorders, 5, 657-665.

Pan, C. Y., \& Frey, G. C. (2006). Physical activity patterns in youth with autism spectrum disorders. Journal of Autism and Developmental Disorders, 36, 597-606.

Pan, C. Y., Tsai, C. L., Chu, C. H., \& Hsieh, K. (2011). Physical activity and self-determined motivation of adolescent with and without 
autism spectrum disorders in inclusive physical education. Research in Autism Spectrum Disorders, 5, 733-741.

Pate, R., Davis, M. G., Robinson, T. N., Stone, E. J., McKenzie, T. L., \& Young, J. C. (2006). Promoting physical activity in children and youth: a leadership role for schools. Circulation, 114, 1214-1224.

Pitetti, K. H., Rendoff, A. D., Grover, T., \& Beets, M. W. (2007). The efficacy of a 9-month treadmill walking program on the exercise capacity and weight reduction for adolescents with severe autism. Journal of Autism and Developmental Disorders, 37, 997-1006.

Reid, P. R., Factor, D. C., Freeman, N. L., \& Sherman, J. (1988). The effects of physical exercise on three autistic and developmentally disordered adolescents. Therapeutic Recreation Journal, 22, 47-56.

Rimmer, J. H. (2006). Use of the ICF in identifying factors that impact participation in physical activity/rehabilitation among people with disabilities. Disability and Rehabilitation, 28, 1087-1095.

Rosenthal-Malek, A., \& Mitchell, S. (1997). Brief report: the effects of exercise on the self-stimulatory behaviors and positive responding of adolescents with autism. Journal of Autism and Developmental Disorders, 27, 193-202.

Schleien, S. J., Heyne, L. A., \& Berken, S. B. (1988). Integrating physical education to teach appropriate play skills to learners with autism: a pilot study. Adapted Physical Activity Quarterly, 5, 182-192.

Schultheis, S., Boswell, B., \& Decker, J. (2000). Successful physical activity programing for students with autism. Focus on Autism and Other Developmental Disabilities, 15(3), 159-162.
Sowa, M., \& Muelenbroek, R. (2012). Effects of physical exercise on autism spectrum disorders: a meta-analysis. Research in Autism Spectrum Disorders, 6, 46-57.

Todd, T., \& Reid, G. (2006). Increasing physical activity in individuals with autism. Focus on Autism and Other Developmental Disabilities, 21, 167-176.

Todd, T., Reid, G., \& Butler-Kisber, L. (2010). Cycling for students with ASD: self-regulation promotes sustained physical activity. Adapted Physical Activity Quarterly, 27, 556-241.

Tomporowski, P. D. (2003). Cognitive and behavioral responses to acute exercise in youths: a review. Pediatric Exercise Science, 15, 348359.

Tomporowski, P. D., Lambourne, K., \& Okumura, M. S. (2011). Physical activity interventions and children's mental function: an introduction and overview. Preventative Medicine, 52, S3-S9.

Watters, R. G., \& Watters, W. E. (1980). Decreasing self-stimulatory behavior with physical exercise in a group of autistic boys. Journal of Autism and Developmental Disorders, 10, 379-387.

World Health Organization. (2013). Adolescent health. Geneva: World Health Organization. Retrieved from: http://www.who.int/topics/ adolescent health/en/.

Zarrett, N., \& Eccles, J.S. (2009). The role of the family and community in extracurricular activity. In L. Shumow (Ed.), AERA Monograph series: promising practices for family and community involvement during high school (vol 4, pp. 27-51). Charlotte, NC: Information Age Publishing Inc. 